\title{
MICROSTRUCTURE AND PROPERTIES OF FINE GRAIN IN718 ALLOY BAR PRODUCTS PRODUCED BY CONTINUOUS ROLLING
}

\author{
${ }^{1}$ Guosheng Chen, ${ }^{1}$ Qingzeng Wang, ${ }^{1}$ Fengjun Liu, ${ }^{1}$ Zixing Wang, ${ }^{2}$ Jianxin Dong, ${ }^{2}$ Xishan Xie \\ ${ }^{1}$ Special Steel Business Unit, Baoshan Iron \& Steel Co. Ltd., Shanghai 200940, China \\ ${ }^{2}$ High Temperature Materials Research Laboratories, University of Science \& Technology \\ Beijing, Beijing 100083, China
}

Keywords: IN718 alloy; Hot continuous-rolling bar; Microstructure; Property

\begin{abstract}
The newly imported high-alloy steel continuous rolling line in Baoshan Iron \& Steel Co. Ltd, which is the first production line in China, was introduced in this paper. The $14 \sim 55 \mathrm{~mm}$ diameter bar hot-rolling procedure has been refined after studying the influences of processing parameters such as micro-structure of continuous rolling billet, rolling start temperature, continuous rolling deformation ratio, rolling line rate, and control cooling parameters on microstructure and properties of IN718 bars. In comparison with traditional open-train mill, this continuous rolling technology provides fine grain bar products with uniform grain structure and reasonable distribution of $\delta$ phase.

Grain size of bar products can be controlled at ASTM 10 in the center and ASTM $11 \sim 11.5$ near the surface by means of this technology. Now this technology is in a stable production condition and the bar products produced provide excellent mechanical properties.
\end{abstract}

\section{Introduction}

For superalloy bars produced by traditional open-train mill, the microstructure and property stability is relatively poor and the products quality is unstable, because the rolling parameters are difficult to control accurately. For IN718 bar products, such problems are very serious because its microstructure should be tightly controlled. To produce IN718 alloy with optimum properties, the grain size should be uniform and maintained at about ASTM 10 and the grain boundaries should be decorated with a certain amount of granular or rod-like $\delta$ phase. Theoretically, to obtain above mentioned structure, in fine-grained billet, the billet should be heated at the $\delta$ phase solves temperature $\left(1005 \sim 1015^{\circ} \mathrm{C}[3,4]\right)$ and hot deformed at about $950^{\circ} \mathrm{C}$ which is a little bit higher than the dynamic recrystallization temperature, and the finish processing temperature should be controlled in the temperature range of $900 \sim 950^{\circ} \mathrm{C}$ [5], which is corresponding with the $\delta$ phase precipitation temperature. In the process of engineering hot working practices, such a technical requirement is easy to be satisfied by die forging and quick upsetting. However, for producing long product, it is usually very difficult to tightly control the exact temperature. Generally, for IN718 alloy hot rolled bars $30 \sim 80 \mathrm{~mm}$ diameter produced through a traditional horizontal roller, under the condition of fully recrystallization and with proper $\delta$ phase precipitation, the grain size can only be refined to ASTM 7 8 [6].Because of the much higher controllability of continuous rolling technology compared with the traditional open-train mill, the structure and property of hot rolled bar products are easy to satisfy optimal value of IN718 technical requirement. Therefore, Baoshan Iron \& Steel Co. Ltd imported high-alloy steel bar continuous rolling line from POMINI of Italy in 2007. 
The continuous hot rolling technology, structure and properties of fine grain IN718 alloy bars products are introduced in this paper, and in comparison with the same size bar products by open-train mill.

\section{Continuous Rolling Equipment and Experimental Material}

The layer of high-alloy steel bar continuous rolling line of Baoshan Iron \& Steel Co. Ltd is shown in Fig.1. This product line includes: continuous heating-furnace(or batch-type furnace) $\rightarrow$ reversing rough rolling mill $\rightarrow$ continuous tunnel furnace $\rightarrow 16$ rack CCR(Compact Cassette Rolling-mill) continuous rolling mill $\rightarrow$ cold controlling $\rightarrow$ cold bed.

The sizes of bars rolled by the continuous rolling mill are ranged from $14 \mathrm{~mm}$ to $85 \mathrm{~mm}$ diameter, dimensional accuracy is $\pm 0.25 \mathrm{~mm}$ (for $<20 \mathrm{~mm}$ diameter) and $\pm 0.90 \mathrm{~mm}$ (for $>80 \mathrm{~mm}$ diameter). The cross section of the billet can be within $110 \sim 140 \mathrm{~mm}$ in edge length, the length can be 2500 $\sim 4000 \mathrm{~mm}$. The billet sizes depend on different type and size bar product requirement. Then, the original billet should be rolled to various geometric sizes and grain structure requirement by rough rolling to produce intermediate billet. The heating temperature control of the intermediate billet is carried out by continuous tunnel furnace. The heating temperature and holding time should be selected according to bar product specification, size and structure requirements. Finally the intermediate billet is rolled to finished products by a CCR continuous rolling mill. In production, different rolling line speed can be selected by certain requirements.

The chemical composition range of experimental IN718 alloys is showed in Table 1. There are 104 groups of bars rolled by open-train mill (horizontal) and 52 groups of bars rolled by continuous rolling mill for statistical confidence. Heat treatment process: $950 \sim 980^{\circ} \mathrm{C} / 1 \mathrm{~h} / \mathrm{AC}+$ $720^{\circ} \mathrm{C} / 8 \mathrm{~h}$, furnace cooled at $50^{\circ} \mathrm{C} / \mathrm{h}$ to $620^{\circ} \mathrm{C} / 8 \mathrm{~h} / \mathrm{AC}$.

The bar sizes rolled by open-train mill are: $14 \sim 20 \mathrm{~mm}$ diameter products rolled by the $250 \mathrm{~mm}$ rolling mill, $21 \sim 45 \mathrm{~mm}$ diameter products rolled by the $300 \mathrm{~mm}$ rolling mill, $\geq 50 \mathrm{~mm}$ diameter bar rolled by the $550 \mathrm{~mm}$ rolling mill.

Microstructure images in this article, unless specifically marked, the up-down direction of the picture is the rolling direction.

Table 1 Chemical composition range of experimental IN718 alloys (wt\%)

\begin{tabular}{ccccccccc}
\hline $\mathrm{C}$ & $\mathrm{Cr}$ & $\mathrm{Mo}$ & $\mathrm{Nb}$ & $\mathrm{Ta}$ & $\mathrm{Al}$ & $\mathrm{Ti}$ & $\mathrm{Ni}$ & $\mathrm{B}$ \\
\hline $0.02-$ & $18.5-$ & \multirow{2}{*}{$3.0-3.2$} & $5.1-5.3$ & $\leq 0.1$ & $0.45-$ & $0.96-$ & $52.5-$ & $0.003-$ \\
0.03 & 19.5 & & & & 0.55 & 1.10 & 53.5 & 0.005 \\
$\mathrm{~S}$ & $\mathrm{P}$ & $\mathrm{Si}$ & $\mathrm{Mn}$ & $\mathrm{Cu}$ & $\mathrm{Co}$ & $\mathrm{O}$ & $\mathrm{N}$ & $\mathrm{Fe}$ \\
$<0.002$ & $<0.015$ & $<0.35$ & $<0.35$ & $<0.30$ & $<1.0$ & $<0.001$ & $<0.008$ & $\mathrm{Bal}$ \\
\hline
\end{tabular}




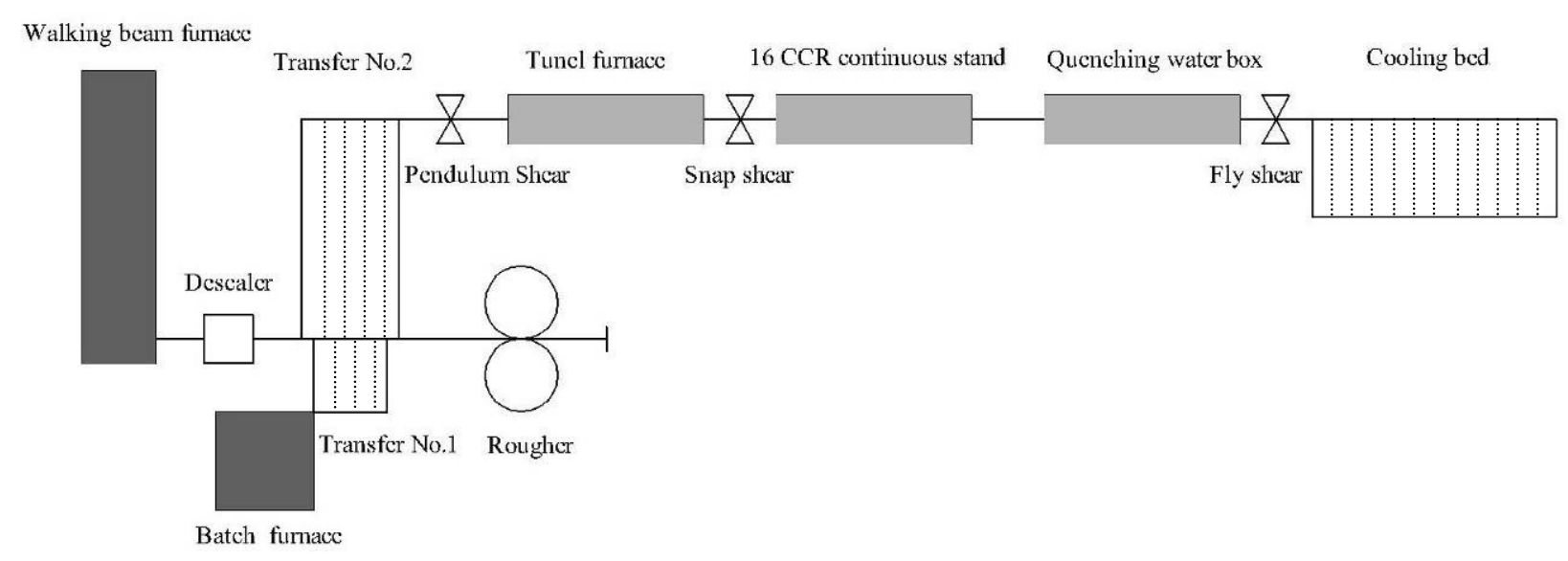

Figure 1. Lay-out of high-alloy steel bar continuous rolling line

\section{Experimental Results}

\section{The Influence of Continuous Rolling Processing Parameter}

The continuous rolling mill equipment has been put in production since 2007. The influences of processing parameters (rolled by rough mill) such as microstructure of continuous rolling billet, rolling start temperature, continuous rolling deformation ratio, rolling line rate and controlled cooling methods on microstructure and properties of IN718 bars is studied by numerical simulation and engineering experiments.

In production of large size bars, to obtain uniform fine grain structure by continuous rolling, fine grain billet should be prepared by rough rolling. If the billet surface temperature drops too much during the rough rolling process, the original billet grain size coarser than ASTM 4 will be retained near the surface of intermediate billet. As shown in Figure 2 and 3 for $45 \mathrm{~mm}$ diameter bar production, if there are original coarse grains at the surface of intermediate billet during rough rolling, although the rolling start temperature and line speed are enhanced at continuous rolling process, the recrystallized grains at the surface can reach about ASTM 10, but the coarse grains can not be completely recrystallized.

With a proper rough rolling temperature and line speed at continuous rolling process, there is a critical deformation ratio which can produce the finest grain size. If the deformation ratio is higher than this critical value, grains will be coarsened because of the enhanced inner temperature rising effect [7].

If the billet temperature is too high at the rolling process, then grains grow and the amount of $\delta$ phase will be reduced. In some cases there may be no $\delta$ phase at grain boundaries in the bar center. If the rough rolling temperature is too low or the line speed is too slow, this low temperature at surface or even at mid-radius incompletely recrystallized grains maybe retained and unexpected precipitation of $\delta$ phase. The above mentioned effect will be more obvious when the bar size is increased. 


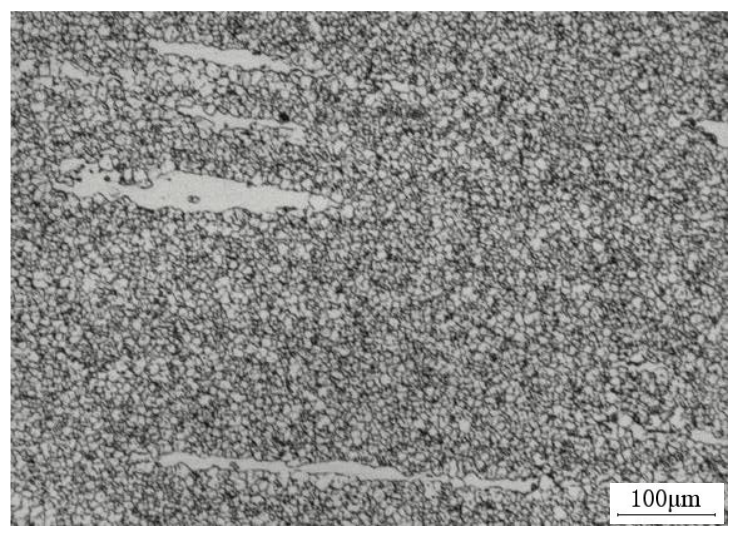

Figure 2. Incompletely recrystallized grain structure in the zone $5 \mathrm{~mm}$ distance to the surface of continuous rolled $45 \mathrm{~mm}$ diameter bar. The intermediate billet characterizes with the grain size coarser than ASTM 4 near surface. (The left-right direction is the rolling direction)

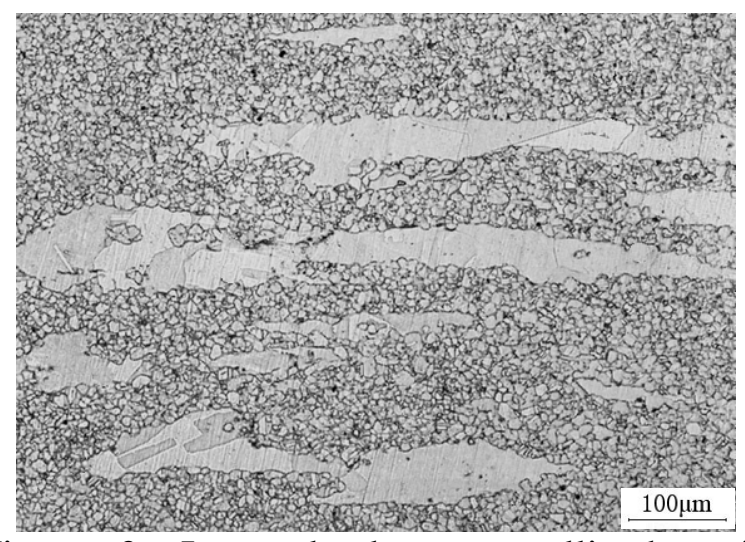

Figure 3. Incompletely recrystallized grain structure in the zone $5 \mathrm{~mm}$ distance to the surface of continuous rolling $\Phi 45 \mathrm{~mm}$ diameter when the rough rolling temperature or line speed is too low. (The left-right direction is the rolling direction)

After producing many groups of IN718 alloy rolled $14 \sim 55 \mathrm{~mm}$ diameter bars, the optimum hotrolling parameters have been refined. Consequently, it is now allowable to produce IN718 alloy bars with various required grain sizes and $\delta$ phase distribution.

2.2 Microstructure and Properties of Fine Grain IN718 Alloy Bar Products Produced by Continuous Rolling

Fine grain IN718 alloy $14 \sim 55 \mathrm{~mm}$ diameter bars can be produced with grain size ASTM 10 in the center by continuous rolling under certain procedures. Grain structure and $\delta$ phase precipitation behavior of 14, 25 and 55mm diameter bars are shown in Figure $4 \sim$ Figure 9 . It is shown that these grains are uniform and fine from the center to surface. Granular or rod-like $\delta$ phase precipitates homogeneously at the grain boundaries. The precipitation of $\delta$ particles near the surface of the bars seems to be slightly more than that in the center. 


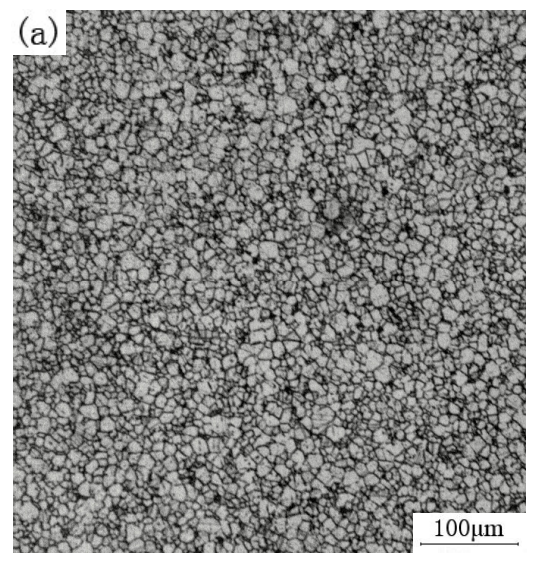

(a) at center

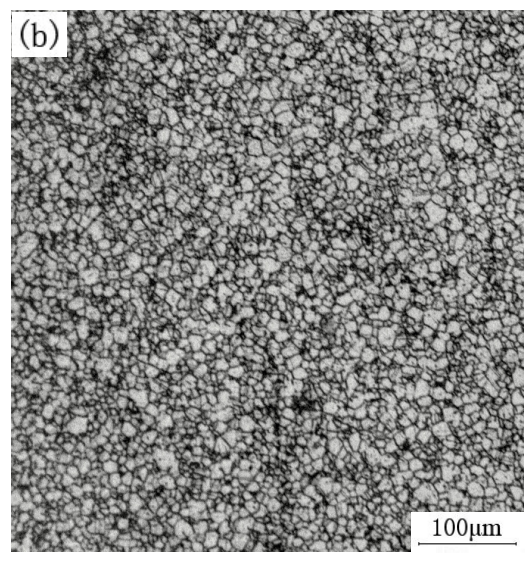

(b) at mid-radius

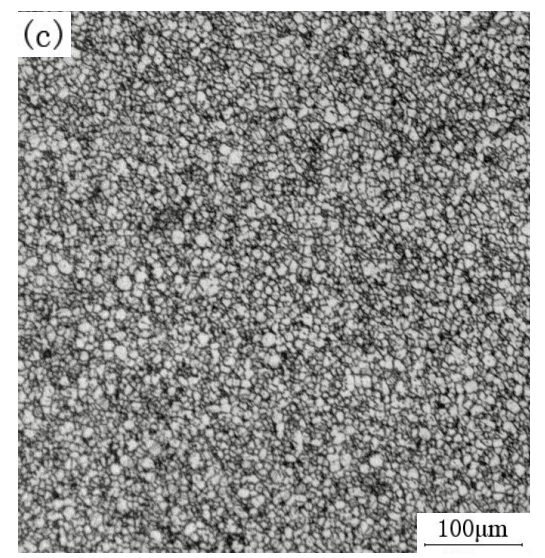

(c) at $1 \mathrm{~mm}$ distance to surface

Figure 4. Grain structure of $14 \mathrm{~mm}$ diameter bars produced by continuous rolling

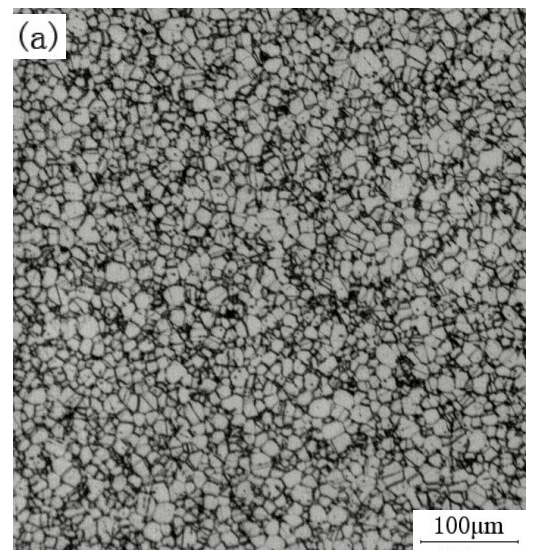

(a) at center

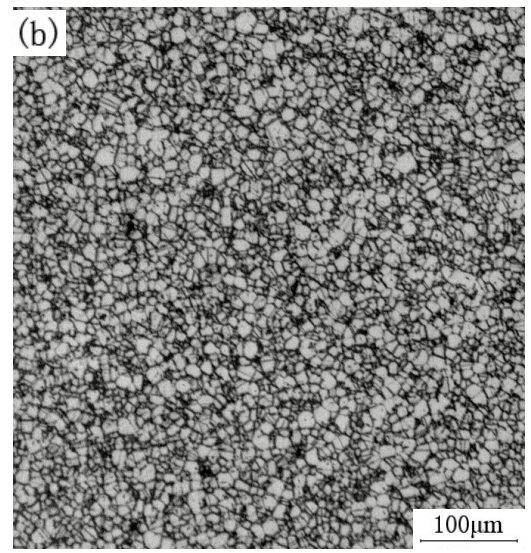

(b) at mid-radius

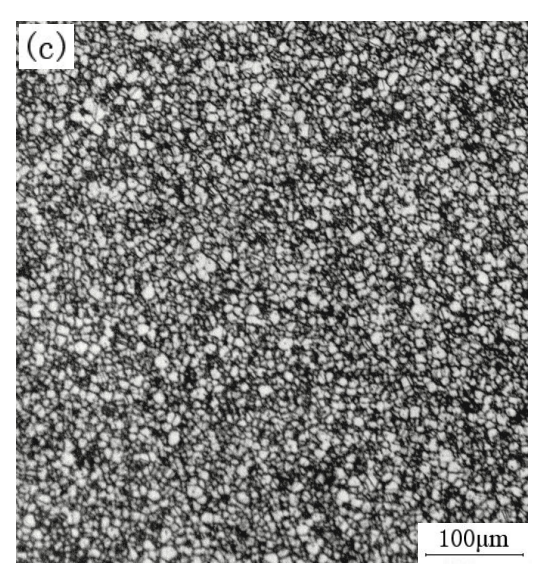

(c) at $1 \mathrm{~mm}$ distance to surface

Figure 5. Grain structure of $25 \mathrm{~mm}$ diameter bars produced by continuous rolling

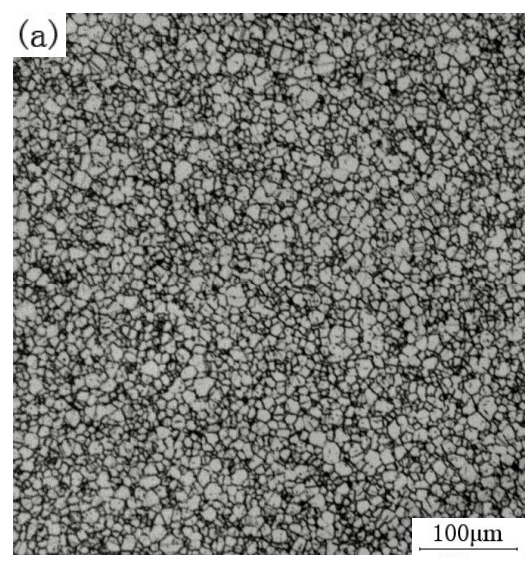

(a) at center

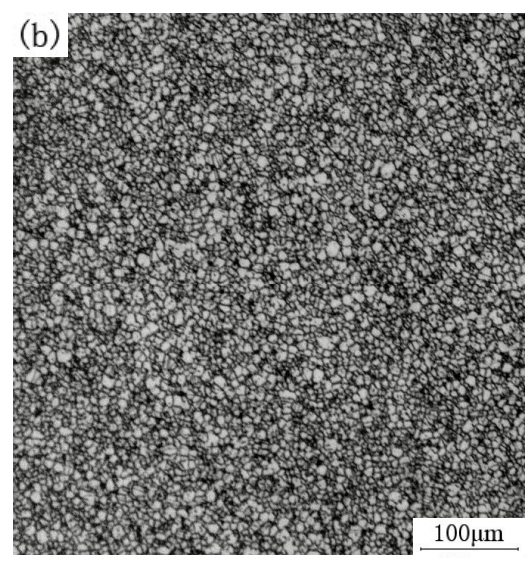

(b) at mid-radius

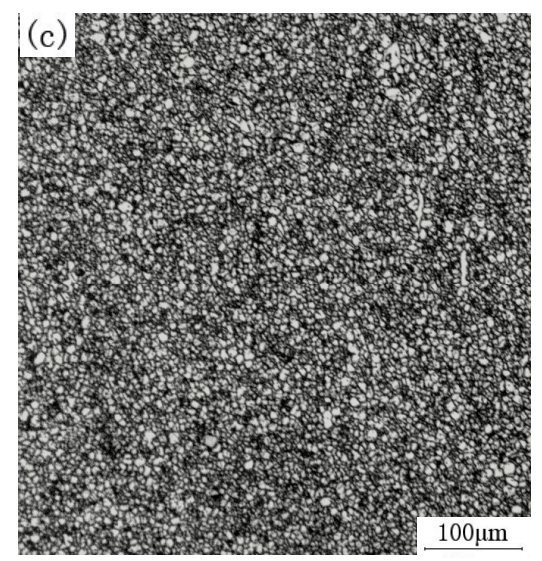

(c) at $1 \mathrm{~mm}$ distance to surface

Figure 6. Grain structure of $55 \mathrm{~mm}$ diameter bars produced by continuous rolling 


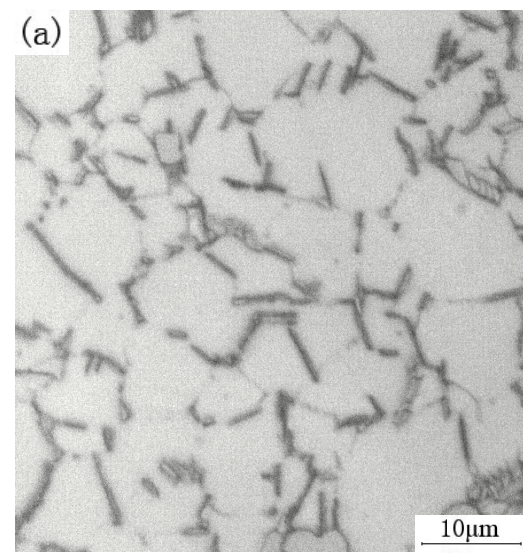

(a) at center

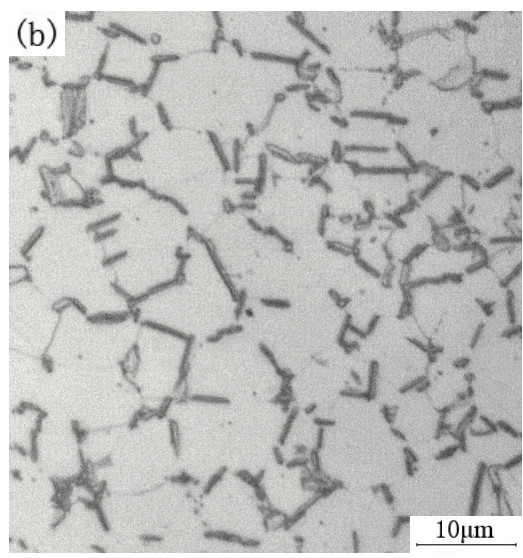

(b) at mid-radius

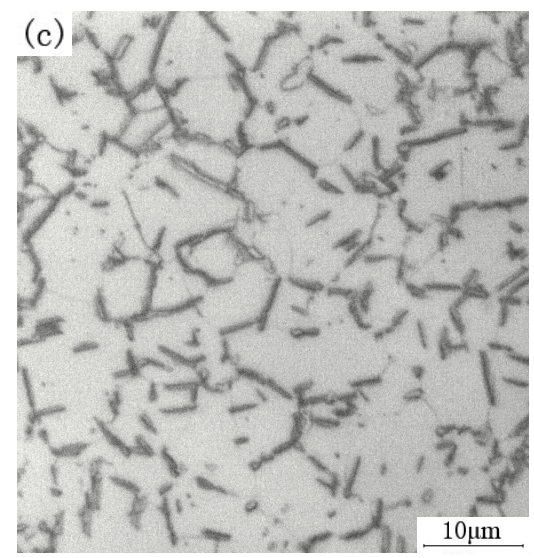

(c) at $1 \mathrm{~mm}$ distance to surface

Figure 7. $\delta$ phase precipitation at different position of $14 \mathrm{~mm}$ diameter bars produced by continuous rolling

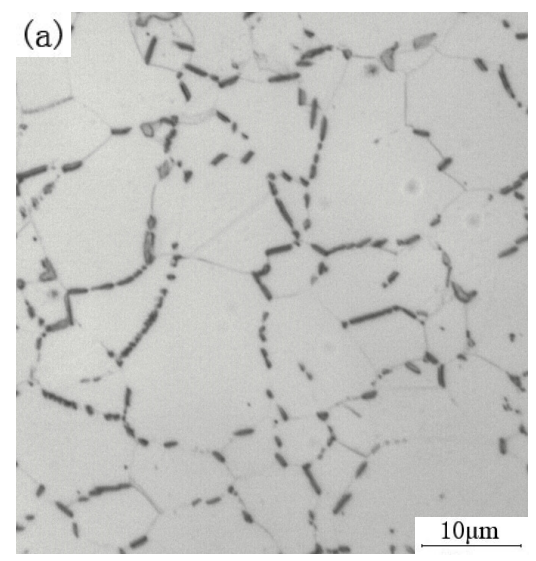

(a) at center

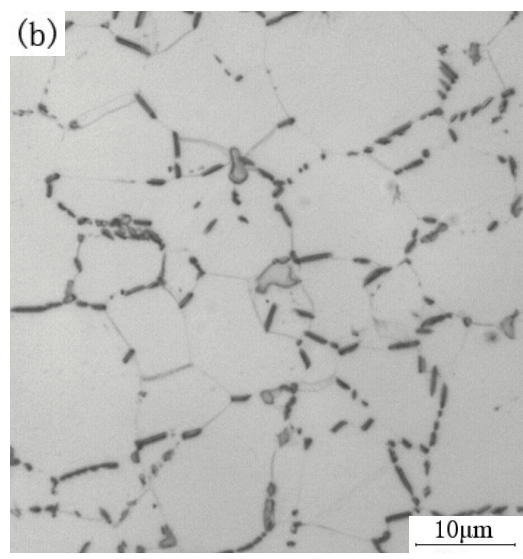

(b) at mid-radius

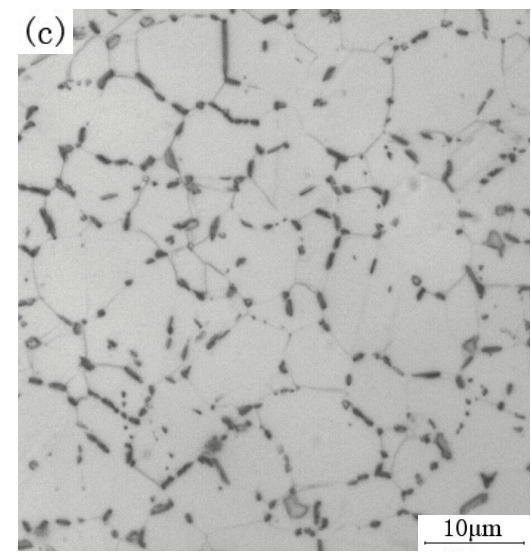

(c) at $1 \mathrm{~mm}$ distance to surface

Figure $8 . \delta$ phase precipitation at different positions of $25 \mathrm{~mm}$ diameter bars produced by continuous rolling

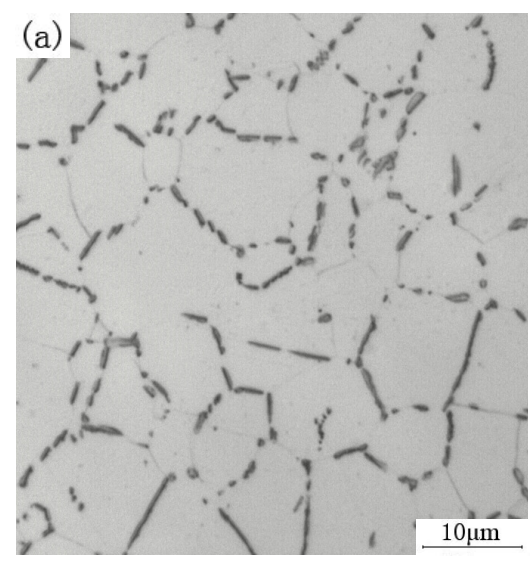

(a) at center

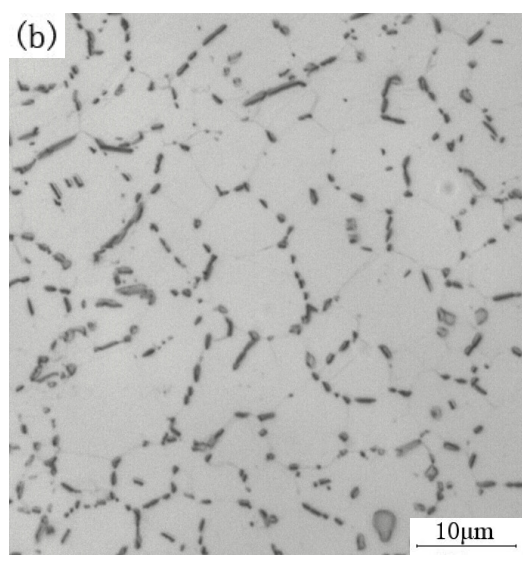

(b) at mid-radius

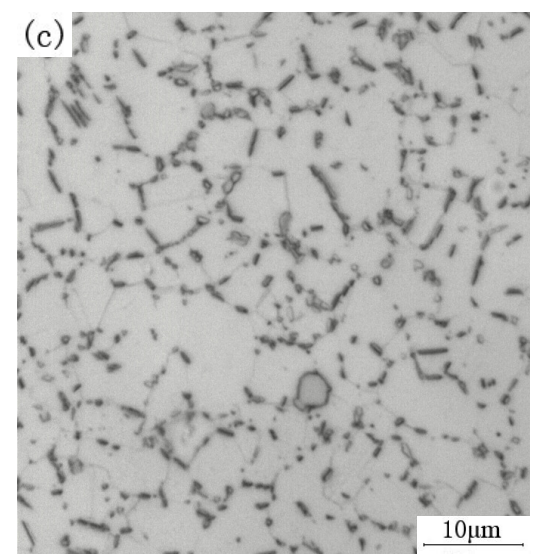

(c) at $1 \mathrm{~mm}$ distance to surface

Figure $9 . \delta$ phase precipitation at different positions of $55 \mathrm{~mm}$ diameter bars produced by continuous rolling 


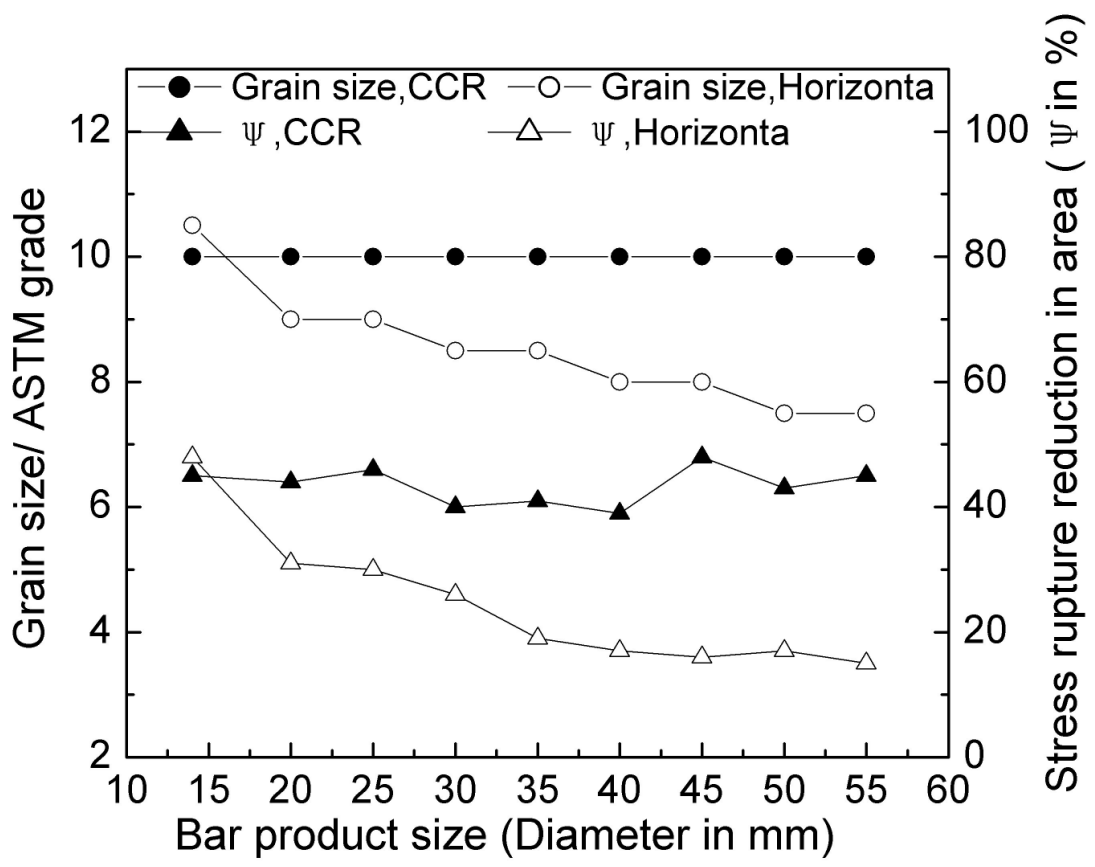

Figure 10. The comparison of center grain size, stress-rupture $\left(650^{\circ} \mathrm{C} / 690 \mathrm{MPa}\right)$ reduction in area of different bar sizes produced by CCR and open-train mill (Horizontal)

Figure 10 shows the comparison of grain size, stress-rupture plasticity of different size IN718 alloy bars produced by continuous rolling and open-train mill. At the center of the bars produced by continuous rolling, the grain size ASTM 10 and stress-rupture plasticity is also very good; but for the bars produced by open-train mill, the grain size is much larger and the stress-rupture plasticity is reduced with the increasing size of bars. The grains of different position for different sizes of IN718 alloy bar rolled by two kinds of rolling methods are shown in Table II. It shows that fine grain structure (ASTM 10 or finer) can be obtained at the bar center, mid-radius and surface by continuous rolling. The grain size varied only ASTM $1 \sim 1.5$ grade from surface to center. However the grain size variation between surface and center for bars produced by opentrain mill are relatively large.

Table II ASTM grain size of different size bars rolled by two rolling technology

\begin{tabular}{|c|c|c|c|c|c|c|c|c|c|c|c|c|}
\hline \multirow{2}{*}{$\begin{array}{c}\text { Rolling } \\
\text { Technology }\end{array}$} & \multicolumn{3}{|c|}{$\Phi 14 \mathrm{~mm}$} & \multicolumn{3}{|c|}{$\Phi 25 \mathrm{~mm}$} & \multicolumn{3}{|c|}{$\Phi 45 \mathrm{~mm}$} & \multicolumn{3}{|c|}{$\Phi 55 \mathrm{~mm}$} \\
\hline & Cent. & $\mathrm{R} / 2$ & Surf. & Cent. & $\mathrm{R} / 2$ & Surf. & Cent. & $\mathrm{R} / 2$ & Surf. & Cent. & $\mathrm{R} / 2$ & Surf. \\
\hline CCR & 10 & 10 & 11 & 10 & 10.5 & 11 & 10 & 10.5 & 11 & 10 & 11 & 11.5 \\
\hline Horizontal & 10.5 & 11 & 12 & 9 & 9.5 & 11 & 8 & 8.5 & 10 & 7.5 & 8.0 & 9.5 \\
\hline
\end{tabular}

Note: Surf. means "Surface", which is $1 \mathrm{~mm}$ distance to the bar surface (before grinding); R/2 means "Mid-radius"; Cent. means "Center".

It is also shown in Table II and Figure 10 that if the bars are rolled by open-train mill, only for bars with the diameters smaller than $25 \mathrm{~mm}$ diameter a grain structure finer than ASTM 9 can be obtained. With the increasing of bar sizes, it becomes more and more difficult to obtain grain structure finer than ASTM 9. Practically, when the bar size is larger than $35 \mathrm{~mm}$ diameter, it is very difficult to obtain grain structures finer than ASTM 8.5. Moreover, for the bars smaller than 
$14 \mathrm{~mm}$ diameter processed by open-train mill and $20 \mathrm{~mm}$ diameter bars under better control for years, although grain structure reached ASTM 10 or finer, due to long rolling time and quick temperature drop, the precipitation of needle-like and granular $\delta$ phase at the surface, mid-radius and center position was enhanced, which resulted in reduced room-temperature plasticity.

Table Ш shows mechanical properties of IN718 alloy of $14 \mathrm{~mm}, 25 \mathrm{~mm}, 55 \mathrm{~mm}$ diameter bars rolled by two kinds of rolling methods. It can be seen that high-temperature properties of bars $14 \mathrm{~mm}$ diameter rolled by two kinds of rolling methods varied slightly. However, the roomtemperature plasticity of bars rolled by open-train mill is obviously lower than CCR because of too much $\delta$ phase precipitated. For the $25 \mathrm{~mm}$ diameter bars, high-temperature properties especially stress rupture plasticity of bars produced by CCR is higher. For 55mm diameter bars produced by CCR, the stress rupture plasticity almost doubled when compared to bars produced by the open-train mill. Moreover, the industrial production statistical data show that microstructure and mechanical properties are stable for bar production by continuous rolling technology. The stress-rupture notch sensitivity is not evident with CCR. However in the process of traditional open-train mill rolling, it often results in stress-rupture notch sensitivity.

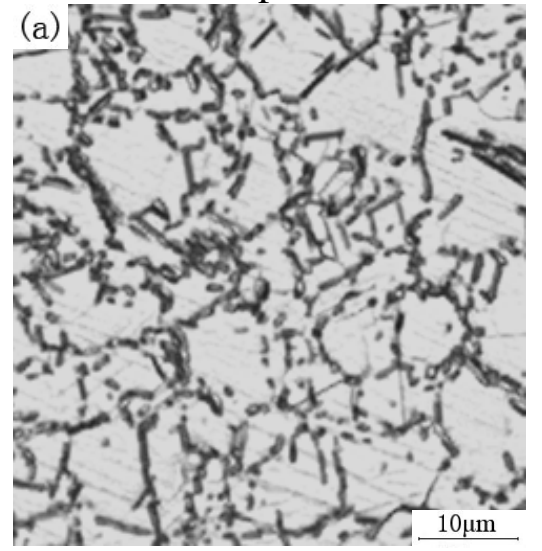

(a) at center

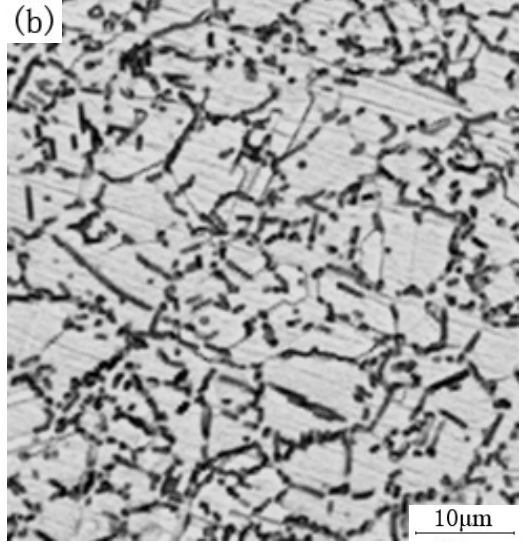

(b) at mid-radius

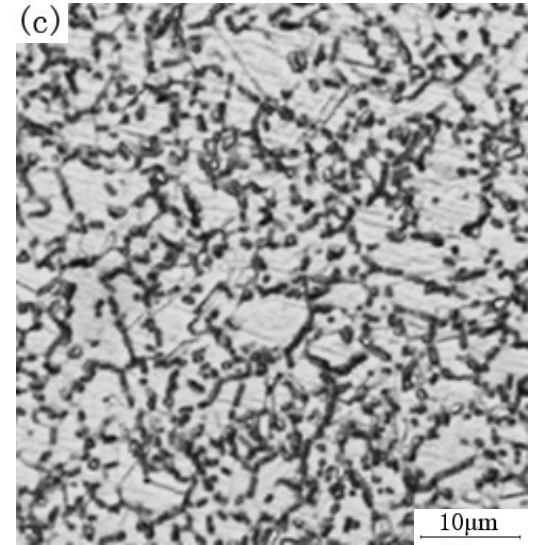

(c) at $1 \mathrm{~mm}$ distance to surface

Figure $11 . \delta$ phase precipitation behavior at different positions of $14 \mathrm{~mm}$ diameter bars rolled by open-train mill

Table Ш Mechanical properties of 14, 25 and 55mm diameter bars rolled by different rolling methods

\begin{tabular}{c|c|ccc|ccc|ccc}
\hline \multirow{3}{*}{$\begin{array}{c}\text { Bar Dia. } \\
\text { mm }\end{array}$} & \multirow{3}{*}{ Rolling } & \multicolumn{3}{|c|}{ Tensile Results } & \multicolumn{3}{c|}{ Tensile Results } & \multicolumn{3}{c}{ Stress Rupture Testing* } \\
\cline { 3 - 10 } & Method & \multicolumn{3}{c|}{$20^{\circ} \mathrm{C}$} & \multicolumn{3}{c}{$650^{\circ} \mathrm{C}$} & \multicolumn{3}{c}{$650^{\circ} \mathrm{C} / 690 \mathrm{MPa}$} \\
\cline { 3 - 11 } & & $\mathrm{US}$ & $\mathrm{El}$ & $\mathrm{AR}$ & $\mathrm{US}$ & $\mathrm{El}$ & $\mathrm{AR}$ & Duration & $\mathrm{El}$ & $\mathrm{AR}$ \\
& & $\mathrm{MPa}$ & $\%$ & $\%$ & $\mathrm{MPa}$ & $\%$ & $\%$ & $\mathrm{~h}$ & $\%$ & $\%$ \\
\hline \multirow{2}{*}{14} & $\mathrm{CCR}$ & 1425 & 26 & 47 & 1160 & 25 & 50 & 79 & 22 & 45 \\
& Horizontal & 1470 & 19 & 38 & 1170 & 27 & 56 & 82 & 24 & 48 \\
& CCR & 1465 & 23 & 44 & 1150 & 22 & 49 & 78 & 23 & 46 \\
& Horizontal & 1460 & 22 & 45 & 1165 & 20 & 41 & 75 & 18 & 30 \\
& CCR & 1435 & 21 & 42 & 1155 & 26 & 43 & 76 & 20 & 45 \\
& Horizontal & 1420 & 22 & 47 & 1145 & 17 & 30 & 80 & 8 & 15 \\
\hline
\end{tabular}

$*$ Lasting to $25 \mathrm{~h}$ after the test, every $12 \mathrm{~h}$ to increase $35 \mathrm{MPa}$. 
This continuous hot rolling line provided higher accuracy in sizes control, high product yield and also production efficiency.

\section{Discussions}

For IN718 alloy bars with fine grain structure produced by traditional open-train mill methods, the heating temperature must be controlled at a lower level. However, it is difficult to be rolled through one heat because of difficulties in roll feed. Bar rolled with one heat results in an incompletely recrystallized, cold-deformation microstructure and needle-like $\delta$ phase, which will embrittle the material because the surface (even center and mid-radius) temperature decreases too quickly during the long time rolling. The technology of low-temperature heating by opentrain mill can not be widely used in production. Actually in the process of industrial rolling by open-train mill, generally the heating temperature is nearly $1120^{\circ} \mathrm{C}$, which develops coarse grains. IN718 alloy billet with original coarse grains of ASTM 2, results in a high deformation resistance and the dynamic recrystallization can not fully completed even at the condition of more than $80 \%$ deformation at $950^{\circ} \mathrm{C}$. During the rolling process, if deformation goes too fast, the temperature in the bar center positions will increase early during the intermediate rolling process and the material will develop coarse recrystallized grains. Moreover, the increasing of finish rolling temperature will decrease the amount of $\delta$ phase, possibly totally solution the $\delta$ phase. Such effect will be more obvious for bigger size bars. If this operation is too slow, there will be a large fraction of cold-deformation microstructure and $\delta$ phase precipitation, which may result in surface cracking and hard roll feed because the surface temperature decreases too fast. This balance is very difficult to manage when producing the uniform fine grain structure and good surface quality required for completing rolling process. Except that man-power factors are extensive, technology parameters such as rolling speed, rolling start temperature, process temperature and finishing temperature are difficult to be reliably controlled.

The present continuous rolling technology provides high-temperature heating in a continuous furnace, low-temperature heating in tunnel furnace and selection of the billet size which can obtain a large amount of deformation and high efficiency, and it can also maintain the original grain size of billet within a small variation before continuous rolling, providing a decrease in hotworking resistance and refined grain structure. For different size bars, it is easy to control the process temperature and finishing temperature at different positions of billet in a proper range by reasonably choosing, and adjusting technological parameters such as amount of deformation for rough rolling and continuous rolling, heating temperature and holding time in tunnel furnace, line speed of continuous rolling and cooling method etc. This provides a relatively uniform fine grain microstructure, proper amount of $\delta$ phase and good mechanical properties for different size bars rolled with CCR technology. After determination of rolling parameters, it can be automatically processed, so man-power factors are minimized, controllability and stability are much better than the traditional open-train mill process.

For small size bars in the process of traditional open-train mill rolling, the effect of inner heating is small, so it is possible to obtain fine grain structure and high-temperature mechanical properties similar to continuous rolling technology. However in comparison with continuous rolling technology, the total rolling time is longer, the temperature drops quickly in the final rolling stage, resulting in $\delta$ phase precipitation, which deteriorates the room-temperature 
plasticity. The microstructures in the center and at the edge of the bars are always inhomogeneous.

\section{Conclusions}

(1) IN718 alloy $14 \sim 55 \mathrm{~mm}$ diameter fine grain, bars rolled by high-alloy steel CCR continuous rolling line which is located at Special Steel Business Unit of Baosteel, can provide an ASTM 10 grain size in the center of bars, and a completely recrystallized grain structure with ASTM 11 11.5 grain size near the surface. The precipitation of $\delta$ phase in different positions of the bars varied slightly, granular or rod-like $\delta$ phase can be uniformly distribute at grain boundaries providing good mechanical properties.

(2) In comparison with IN718 alloy bar products produced by traditional open-train mill, this continuous rolling technology eliminates the problems such as grain growth with the increasing bar size and difficulty to control $\delta$ phase. The grain size of $30 \sim 55 \mathrm{~mm}$ diameter CCR bars can be refined ASTM $1.5 \sim 2.5$ grade with uniform grain structure, such that the precipitation of $\delta$ phase consistent through the cross-section. The mechanical properties of CCR material are better that processed with the traditional open-train mill, and high-temperature plasticity is obviously enhanced, which becomes more obvious with increasing of bar sizes.

(3) This continuous rolling technology is stable, man-power influence is small, bar product size accuracy and production yield are higher than bars produced by traditional open-train mill.

\section{References}

1. J.Y. Zhuang, et al., The relationship of $\delta$ phase and stress-rupture notch sensitivity. Journal of University Science and Technology Beijing, 1991, (Supl): 177(In Chinese)

2. H.Yuan, W.C. Liu. Effect of the $\delta$-phase on the hot deformation behavior of Inconel 718, Materials Science and Engineering A . Vol. 408, 2005; p.281-289

3. A.D. Saied, Y.W. Liu, W. Richard. Delta phase precipitation in Inconel 718, Materials Characterization, Vol.53, 2004, 7-16

4. D.Y. Cai, H.W. Zhang, P.L. Nie, et al. Dissolution kinetics of $\delta$-phase and its influence on the notch sensitivity of Inconel 718, Materials Characterization, Vol. 58, 2007, 220-225

5. J.Y. Zhuang, J.H Du, Q. Deng et al. The GH4169 Super alloy, Peiking: Metallurgical Industry Press, 2006: 54(In Chinese)

6. M. Walter and A. Tatschl, "Processing of Rolling Technologies for Alloy 718," Superalloys 718, 625, 706 and Various Derivatives, ed. E.A. Loria (Warrendale, PA: TMS, 2005), 111-121.

7. J.Y. Zhang, G.S. Chen, W.L. Zhang and Q.Z. Wang, Effects of Continuous Casting Deformation on Microstructure and Propertis of GH4169 Alloy Bars, Baosteel Technology No.3 2009, 56-60 
8. M.H. Cao et al., "Influences of Deformation Speed and Grain Size on High Temperature Properties and Microstructures of Superalloy GH4169," Journal of Iron and Steel Research, 15(7) (2003), 361-365. 